\title{
The Influence of Early versus Late Cochlear Implantation on the Language Outcomes of Egyptian Arabic Speaking Children with Congenital Bilateral Severe-Profound Sensory-Neural Hearing Loss
} Original

Article

\author{
Elham Shahin ${ }^{1}$, Amira El Shennawy ${ }^{1}$, Ayatallah Raouf Sheikhany', Amira El Tahawy ${ }^{2}$ \\ ${ }^{1}$ ENT Department, Cairo University \\ ${ }^{2}$ Egyptian Ministry of Health
}

\begin{abstract}
Introduction: Young children who experience severe-to-profound sensory-neural hearing loss (SNHL) face challenges in developing spoken language since they are unable to detect acoustic-phonetic cues which are essential for speech recognition.

Aim: The aim of this study was to examine the influence of age at implantation on children's language development to detect whether early intervention with cochlear implantation in children with severe to profound SNHL results in better linguistic outcomes.

Subjects and Methods: 60 children from the cochlear implant unit from the Kasr El Ainy hospital were recruited to participate in this cross sectional study. They suffered from congenital bilateral severe to profound sensori-neural hearing loss since birth. They all had unilateral cochlear implant. Their ages ranged from 2 - 7 years old, 30 of them received cochlear implant prior to 5 years of age and the other 30 children received cochlear implant after 5 years of age. They all underwent formal language assessments.

Results: Comparison between group I \& group II in receptive, expressive and total language ages obtained by the Arabic Language Test with \& without visual cues showed a significant difference between group I (early) and group II(late).
\end{abstract}

Key Words: Cochlear implant, early, language, late

Received: 22 January 2019, Accepted: 07 February 2019

Corresponding Author: Ayatallah Raouf Sheikhany, MD, ENT Department, Cairo University, E-mail: ayasheikhany@gmail.com

ISSN: 2090-0740, March 2019, Vol.20, No.1

\section{INTRODUCTION}

Young children who experience severe-to-profound sensory-neural hearing loss (SNHL) face challenges in developing spoken language since they are unable to detect acoustic-phonetic cues which are essential for speech recognition. This is also the case when they are fitted with traditional amplification devices (hearing aids). Cochlear implantation is the treatment of choice for over half the children identified with early, severe-to-profound SNHL ${ }^{[1]}$.

The cochlear implant candidacy assessment and criteria for selection varies from center to center. Based on the current Food and Drug Adminstration (FDA) guidelines, 'children must present with a significant hearing loss, demonstrate a lack of auditory development with appropriately fit hearing aids, and have no medical contraindications for surgery'. The patient must also undergo a thorough medical work up to exclude any contraindication for surgery ${ }^{[2]}$.
The effect of age at implantation on children's language development has been a major focus of research. Two related issues are frequently discussed and debated in the literature: '(a) whether the command of language in children with CIs will become equivalent to that of their hearing peers by the age of 4-5 years and (b) whether the likelihood of this happening is greater the earlier the children are implanted within the first 4 years of life'. There is evidence that children who are implanted by the age of 24 months make better linguistic progress than the children who are implanted later ${ }^{[3]}$.

One explanation for the better linguistic progress that is expected in children who receive their cochlear implant earlier rather than later due to the concept of the sensitive period $^{[3]}$. According to theories of neuro-cognitive development, there is a period of 'heightened sensitivity for language learning in young humans' ${ }^{[4]}$. 
Infants who hear normally develop spoken language with great ease primarily through their auditory channel. Young infants can detect the differences among various acoustic phonetic units specific to their native language, as well as those of other languages to which they have had no exposure ${ }^{[5]}$.

During the first few years of life, the developing brain largely depends on external stimulation to form meaningful neural connections and a functional network, which can support behavioral learning ${ }^{[6]}$.

When sensory input such as hearing is absent, the consequences on brain development can be devastating. Normal auditory responses from the brain are either delayed or non-existent in deaf humans, indicating that brain maturation is highly dependent upon appropriate stimulation. A cochlear implant can provide a deaf child with the stimulation necessary for the central auditory pathways to develop, cochlear implantation which occurs within a development time period of maximal neuronal plasticity, i.e., a sensitive period, results in the most optimal outcomes for the implanted child ${ }^{[7]}$.

Auditory deprivation caused by deafness has a direct relation to the severe impairment of speech and language development in children ${ }^{[8]}$. The lack of sensory activity which leads to poorer neuro-plasticity is incriminated for that. However, this deleterious effect can be reversed by the provision of sensory stimulation such as delivered by hearing aids or cochlear implantation ${ }^{[9]}$.

Research and observation suggest that spoken language performance outcomes are best for those who are implanted very young when language is typically developing. This is the time when the brain most readily masters language. For children implanted at the youngest ages (prior to 18 months ), spoken language appears to emerge most naturally. As children are implanted at progressively later ages, outcomes and rate of development are varied ${ }^{[10]}$.

For children who have had experience hearing and who have lost their hearing later, a similar rule applies: The shorter the time period of deafness, the more likely they are to benefit from a cochlear implant. Today, children are being implanted at ages as young as their first year of life. Additionally, research has shown better results for children implanted at a very young age $\mathrm{e}^{[11]}$.

Other researchers debate that any child may be able to benefit from a cochlear implant regardless of his or her age. However, for children who have become deaf before learning to speak, success is more likely if they are implanted at a young age ${ }^{[12]}$.

The debate of the appropriate age of implantation continues and up to the authors' knowledge research is still lacking on Egyptian Arabic speaking children to detect the influence of age at the time of implantation on the linguistic outcomes of those children to confirm or cancel the existence of the relation in Arabic speaking populations.

\section{Aim}

The aim of this study was to examine the influence of age at implantation on children's language development to detect whether early intervention with cochlear implantation in children with severe to profound SNHL results in better linguistic outcomes.

\section{SUBJECTS AND METHODS}

Sixty children from the cochlear implant unit from the Kasr El Ainy hospital were recruited to participate in this cross sectional study. They suffered from congenital bilateral severe to profound sensori-neural hearing loss since birth and they all fitted the criteria for cochlear implant candidacy set by the Egyptian National Health Insurance Committee for Cochlear Implantation. They all had unilateral cochlear implant.

Their ages ranged from 2 - 7 years old at the time of the study, 30 of them received cochlear implant prior to 5 years of age and the other 30 children received cochlear implant after 5 years of age.

All 60 children were attending speech language therapy sessions at Phoniatric unit, Kasr El Ainy hospital where this study was performed. The children received their language therapy in frequency twice weekly 1:1 30 minutes sessions. All children were Egyptian Arabic speaking who came from nearly the same socioeconomic standard.

\section{Inclusion criteria for children were as follow:}

1. Scores of IQ assessment is 85 or above.

2. Children with bilateral severe to profound sensoryneural hearing loss and received unilateral cochlear implant.

3. Children received speech, language and auditory training for one year.

4. All children were growing up in a monolingual environment (Arabic language).

5. The children and their parents attended Kasr El Aini hospital for regular language therapy as well as for audiological and technical management of the device.

\section{Exclusion criteria were as follow:}

1. Previous failed cochlear implant.

2. Structural or motor speech problems apparent on oral examination. 
3. Additional developmental disorders (psychologicalneurological-motoric).

\section{Methods:}

Study time: From January 2014 to June 2014.

\section{All children were subjected to the following assessment protocol:}

A. Parent interview and history taking, including personal, family, peri-natal, developmental and medical history.

B. Parent questionnaire: An Arabic questionnaire was devised during initial period of the study and was given to all parents to fill prior to the test of the children. The doctor was present to explain any unclear items and to ensure that all items were fulfilled. The questionnaire consisted of 50 statements, parents were instructed to consider whether they agree or disagree with each statement and indicate their response with number that they think best describe them and their child: 0 indicated Disagree, 1 indicated Neutral and 2 indicated Agree.

Parent questionnaire included the following items:

1. Information about parents.

2. Communication abilities of the child.

3. Social skills of the child.

4. Academic achievement of the child.

5. If cochlear implant change in the future of their child.

6. Rehabilitation demands of their child.

7. Satisfaction of the parents with their child's communication, social and academic abilities.

8. Stresses of parents they feel about their child.
9. Relationships of parents with people surrounding their child.

10. Communication with people surrounding the child.

\section{Standardised Arabic language test: ${ }^{[13]}$}

The test was performed either in one or more sessions according to the ability of the child. The test was done with and without visual cues. The test time ranged from 30 minutes to 1 hour. The test was used to assess: semantic, receptive, expressive, and total language.

D. Modified preschool language scale (Arabic edition) ${ }^{[14]}$

Modified PLS - 4 is composed of two subscales, receptive language scale which is composed of 62 items and expressive language scale which is composed of 71 items. This test was used to assess receptive, expressive and total language. The Total language was obtained by adding both receptive and expressive language.

\section{Statistical Analysis}

Data was analyzed by Microsoft Office 2003 (excel) and Statistical Package for Social Science (SPSS) version 16. Parametric data was expressed as mean $\pm \mathrm{SD}$, and non parametric data was expressed as number and percentage of the total. Comparing the mean $\pm \mathrm{SD}$ of two groups was done using paired and unpaired student's $t$ test. Measuring the mutual correspondence between two values was done using the Spearman correlation coefficient. Determining the extent that a single observed series of proportions differs from a theoretical or expected distribution was done using the Chi square test $\{P$ value $>0.05$ is considered non-significant, $P$ value $<0.05$ is considered significant, $P$ value $<0.01$ is considered highly significant $\}$.

\section{RESULTS:}

Comparison between total, semantic, expressive and receptive language ages with and without visual cues in group (I) as obtained by the Arabic Language Test showed that there was no significant difference between all of them as shown in (Table 1). 
Table 1: Comparison in group I between the assessment of total language age with visual cues and total language age without visual cues as done by Arabic language Test:

\begin{tabular}{|c|c|c|c|c|}
\hline & \multicolumn{2}{|c|}{ Group I } & \multirow[b]{2}{*}{$\mathrm{X}^{2}$} & \multirow[b]{2}{*}{$p$ value } \\
\hline & $\begin{array}{c}\text { With visual } \\
\text { cues }\end{array}$ & $\begin{array}{c}\text { Without } \\
\text { Visual cues }\end{array}$ & & \\
\hline \multicolumn{5}{|c|}{ Total language age } \\
\hline$<2$ Yrs & 7 & 12 & & \\
\hline $2-2.6 \mathrm{yrs}$ & 21 & 16 & $5.676^{\mathrm{a}}$ & 0.129 \\
\hline $2.6-3 \mathrm{yrs}$ & 2 & 2 & & \\
\hline \multicolumn{5}{|c|}{ Semantic Language } \\
\hline $2-2.6 \mathrm{yrs}$ & 6 & 8 & \multirow{6}{*}{$2.794^{\mathrm{a}}$} & \multirow{6}{*}{0.732} \\
\hline $2.6-3 \mathrm{yrs}$ & 8 & 10 & & \\
\hline $3-3.6 \mathrm{yrs}$ & 9 & 5 & & \\
\hline $3.6-4 \mathrm{yrs}$ & 3 & 4 & & \\
\hline $4-4.6 \mathrm{yrs}$ & 3 & 3 & & \\
\hline $4.6-5 \mathrm{yrs}$ & 1 & 0 & & \\
\hline \multicolumn{5}{|c|}{ Expressive language } \\
\hline$<2 \mathrm{Yrs}$ & 8 & 16 & \multirow{3}{*}{$4.800^{\mathrm{a}}$} & \multirow{3}{*}{0.091} \\
\hline $2-2.6 \mathrm{yrs}$ & 19 & 11 & & \\
\hline $2.6-3 \mathrm{yrs}$ & 3 & 3 & & \\
\hline \multicolumn{5}{|c|}{ Receptive language age } \\
\hline$<2 \mathrm{Yrs}$ & 19 & 25 & \multirow{2}{*}{$3.068^{\mathrm{a}}$} & \multirow{2}{*}{0.080} \\
\hline $2-2.6 \mathrm{yrs}$ & 11 & 5 & & \\
\hline
\end{tabular}

Comparison between total, semantic, expressive and receptive languages with visual and without visual cues in group (II) ages as obtained by the Arabic Language Test showed that there was no significant difference between all of them as shown in (Table 2).

Table 2: Comparison in group II between assessment of total language age with visual cues and total language age without visual cues as done by Arabic language Test

\begin{tabular}{|c|c|c|c|c|}
\hline \multirow{2}{*}{$\begin{array}{c}\text { Total } \\
\text { language } \\
\text { age }\end{array}$} & \multicolumn{2}{|c|}{ Group II } & \multirow[b]{2}{*}{$\mathrm{X}^{2}$} & \multirow[b]{2}{*}{$p$ value } \\
\hline & $\begin{array}{l}\text { With visual } \\
\text { cues }\end{array}$ & $\begin{array}{c}\text { Without } \\
\text { Visual cues }\end{array}$ & & \\
\hline$<2$ Yrs & 22 & 23 & \multirow{2}{*}{$0.089^{\mathrm{a}}$} & \multirow{2}{*}{0.766} \\
\hline $2-2.6 \mathrm{yrs}$ & 8 & 7 & & \\
\hline \multicolumn{5}{|c|}{ Semantic Language } \\
\hline$<2$ Yrs & 5 & 8 & \multirow{6}{*}{$1.983^{\mathrm{a}}$} & \multirow{6}{*}{0.739} \\
\hline $2-2.6 \mathrm{yrs}$ & 15 & 15 & & \\
\hline $2.6-3 \mathrm{yrs}$ & 6 & 5 & & \\
\hline $3-3.6 \mathrm{yrs}$ & 1 & 0 & & \\
\hline $3.6-4 \mathrm{yrs}$ & 3 & 2 & & \\
\hline $4.6-5 \mathrm{yrs}$ & 1 & 0 & & \\
\hline \multicolumn{5}{|c|}{ Expressive language } \\
\hline$<2$ Yrs & 25 & 26 & \multirow{2}{*}{$0.131^{\mathrm{a}}$} & \multirow{2}{*}{0.718} \\
\hline $2-2.6 \mathrm{yrs}$ & 5 & 4 & & \\
\hline \multicolumn{5}{|c|}{ Receptive language age } \\
\hline$<2$ Yrs & 28 & 30 & \multirow{2}{*}{$0.089^{\mathrm{a}}$} & \multirow{2}{*}{0.766} \\
\hline $2-2.6 \mathrm{yrs}$ & 2 & 0 & & \\
\hline
\end{tabular}

The results obtained for the Modified preschool language scale (Arabic edition) showed significant difference between group ( I ) and group ( II ) in receptive language (mean in group ( I ) was (26.2) and group ( II ) was (23.7), expressive language (mean in group ( I ) was (26.1) and group ( II ) was (24.1) and total language (mean in group ( I ) was (26.1) and group ( II ) was (23.8). There was significant difference between group ( I ) and group ( II ) in favor of group I which means that cochlear implantation before 5 years gave better results than later implantation as shown in (Table 3 ).

Table 3: Comparison between Group I and Group II in receptive, expressive and total language ages by the Modified preschool language scale (Arabic edition)

\begin{tabular}{cccccc}
\hline & GROUPS & Mean & $\begin{array}{c}\text { Std. } \\
\text { Deviation }\end{array}$ & T value & P value \\
\hline $\begin{array}{c}\text { Receptive } \\
\text { language } \\
\text { Age }\end{array}$ & Group I & 26.2000 & 3.75454 & & \\
$\begin{array}{c}\text { Expressive } \\
\text { language } \\
\text { Age }\end{array}$ & Group II & 23.7667 & 5.41825 & 2.022 & .048 \\
$\begin{array}{c}\text { Total } \\
\text { language } \\
\text { Age }\end{array}$ & Group II & 24.1000 & 4.50555 & 1.931 & .059 \\
\hline
\end{tabular}

Comparison between group I and group II in receptive language ages obtained by the Arabic Language Test with and without visual cues showed a significant difference between group I and group II as shown in (Figures 1 and 2).

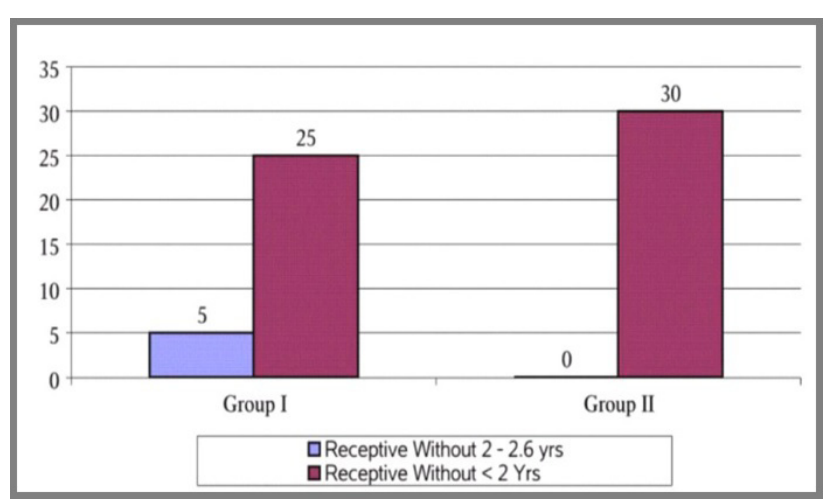

Fig. 1: Comparison between group I and group II in receptive language assessment without visual cues

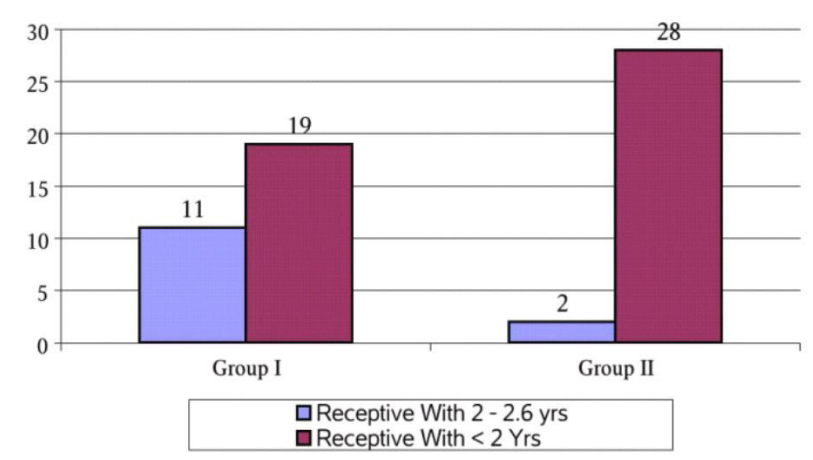

Fig. 2: Comparison between group I and group II in receptive language assessment with visual cues 
Comparison between group I and group II in expressive language ages obtained by the Arabic Language Test with and without visual cues showed a significant difference between group I and group II as shown in (Figures 3 and 4).

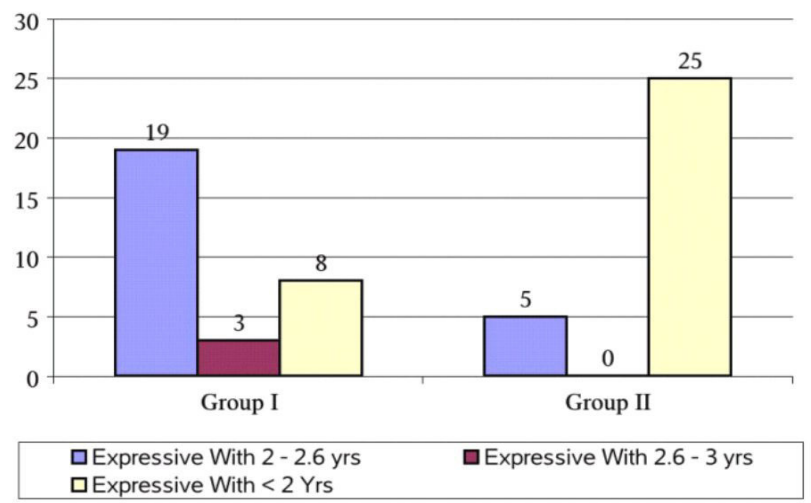

Fig. 3: Comparison between group I and group II in expressive language assessment with visual cues

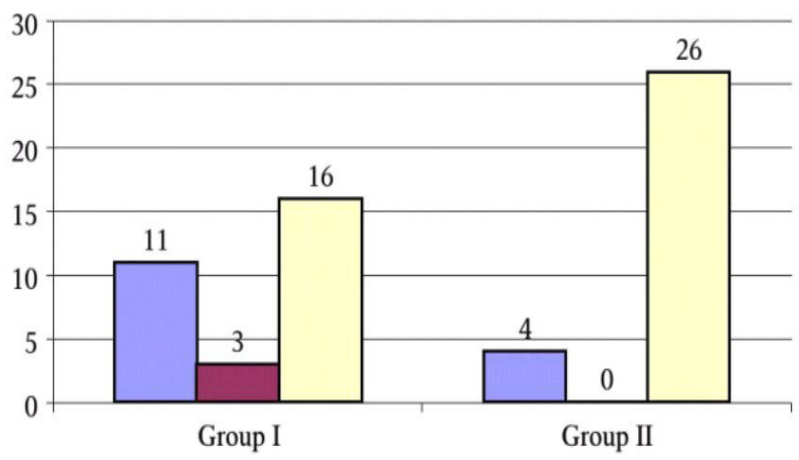

$\square$ Expressive 2 - 2.6 yrs $\square$ Without 2.6 - 3 yrs $\quad \square$ Without $<2$ Yrs

Fig. 4: Comparison between group I and group II in expressive language assessment without visual cues

Comparison between group I and group II in total language ages obtained by the Arabic Language Test with and without visual cues showed a significant difference between group I and group II as shown in (Figures 5 and 6).

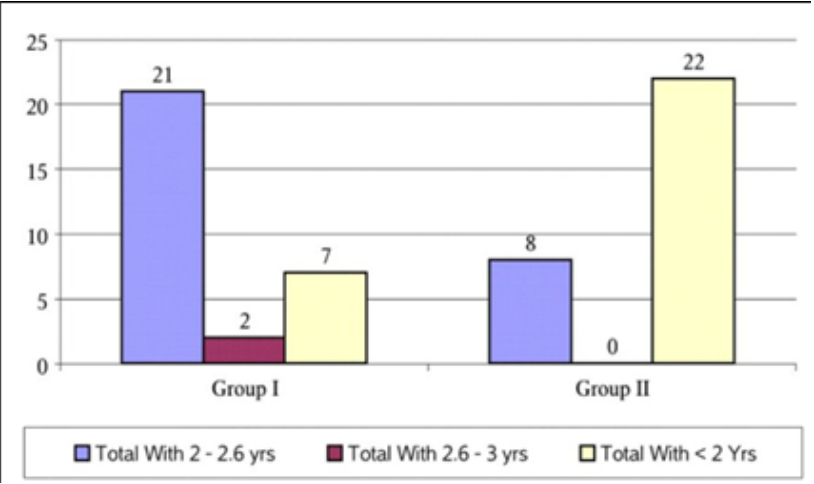

Fig. 5: Comparison between group I and group II in total language assessment with visual cues

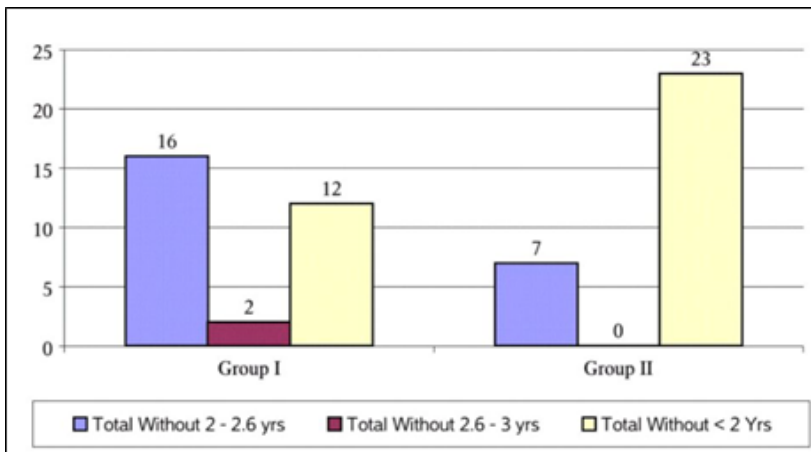

Fig. 6: Comparison between group I \& group II in total language assessment without visual cues

The questionnaire in this study showed no significant difference between parents of both group in all statements except in statement 10, 11 and 31. Statement no. 10 which is "Does Not need to look at the speaker's face", Statement no. 11 which is "Does Not need to use sign language at all" and Statement no.31 which is "Satisfied with my child's communications abilities". These three statements showed a significant difference between group I and group II.

\section{DISCUSSION}

The sooner the children with hearing loss received cochlear implant, the better their language outcome was ${ }^{[4]}$, this statement is in agreement with other recent studies which reported that age of implantation ranged from 6 to 48 months due to the concept of sensitive period. The exact end point of this period is not known, the gradual decrease in the brain sensitivity above the age of 4 years old is a fact $^{[4]}$.

The assessment of receptive and expressive language skills in this study was done with visual cues and without visual cues to assess the discrepancy between the auditory only versus auditory and visual channels in combination to process spoken language. There was a significant difference in the results obtained between group I and group II which indicated that group I was mainly depending on their auditory channels for listening and developing spoken language more than group II. This is more natural and is in favor of better outcomes obtained and more chance at closing the gap earlier than group II.

Comparison between group I and group II in receptive, expressive and total language ages obtained by the Arabic Language Test with and without visual cues showed a significant difference between group I and group II as shown in (Figure 1,2,3,4,5 and 6).

This is in agreement with theory of ${ }^{[15]}$ who stated that 'children fitted with cochlear implants at an early age improve their expressive and receptive language abilities and have been shown to develop speech and language skills at an equivalent rate as normal hearing children'. 
When comparing the results obtained with and without visual cues for each group, a different point was raised. The intra-group comparison showed no differences between visual and auditory combined and auditory only for both groups.

Comparison between total, semantic, expressive and receptive language ages with and without visual cues in group (I) \& (II) as obtained by the Arabic Language Test showed that there was no significant difference between all of them as shown in (Table 1and 2).

This is in agreement with ${ }^{[12]}$ who stated in 2008 that children benefit from cochlear implantation regardless of their age. So when comparing children in each group with themselves the results were different from when comparing them with children in the other group and the comparison was always in favor of the younger group.

The results obtained for the Modified preschool language scale (Arabic edition) showed significant difference between group ( I ) and group ( II ) in receptive, expressive, and total language scores in favor of group I which supports the hypothesis that cochlear implantation before 5 years gave better results than later implantation as shown in (Table 3).

This is in agreement with ${ }^{[16]}$ who mentioned that children receive auditory information at a time when their brain is especially ready to learn language. In most cases, when children with a profound hearing impairment are implanted early enough, their hearing and speech develop similar to that of their hearing peers. In these cases, spoken language appears to emerge almost naturally.

The results obtained from the parent questionnaire in this study give a different perspective. It showed no significant difference between parents of both group in all statements except in statement 10, 11 and 31. Statement no. 10 which is "Does Not need to look at the speaker's face", Statement no.11 which is "Does Not need to use sign language at all“" and Statement no.31 which is "Satisfied with my child's communications abilities". These three statements showed a significant difference between group I and group II. These results state that although all the children in this study didn't close the gap with their hearing peers in terms of spoken language production and academic achievement; their parents were almost equally satisfied with their children. The questionnaire pointed to dependence of group 11 on visual cues but it did not reach sig level as proved by intra group results ${ }^{[17]}$. stated that some school aged children with cochlear implant received prior to the age of five years have been reported to be "closing the gap" with their hearing peers in terms of spoken language production and academic achievement.

The results of this study are supportive of the recent trend towards early cochlear implantation 'the earlier the implantation the better the outcomes'.

\section{Limitations:}

This study only sheds light on the performance of a relatively small number of cochlear implanted children at a given time, longer longitudinal prospective larger scale multi-centric studies are needed to adequately assess their progress and the outcomes during the first few years post implantation. Another limitation is that no linguistic profile before therapy or implantation was available to compare its effect on the post-operative outcomes.

\section{CONFLICT OF INTEREST}

There are no conflict of interest

\section{REFERENCES}

1. Bradham T, Jones J. Cochlear implant candidacy in the United States: prevalence in children 12 months to 6 years of age. Int J Pediatr Otorhinolaryngol 72(7):1023-1028, 2008.

2. Bradham T, Snell G, Haynes D. Current practices in pediatric cochlear implant. ASHA (19) 32- 42, 2009.

3. Holt RF, Svirsky MA . An exploratory look at pediatric cochlear implantation: Is earliest always best? Ear and Hearing, ( 29) : 492-511, 2008.

4. Mayberry RI, Early language acquisition and adults language ability : what sign language reveals about the critical period for language, The Oxford Handbook of Deaf Studies, Language, and Education, Vol. 2 ( chapter2) Pp. 281 - 291, 2010 .

5. Gravel JS, O'Gara J, communication options for children with hearing loss, mental retardation and development disabilities, Mental Retardation and Developmental Disabilities Research Reviews (9) 243 - 251, 2003.

6. Pallas SL. Intrinsic and extrinsic factors that shape neocortical specification. Trends Neurosci. 24(7):417-423, 2001.

7. Eggermont JJ, Ponton CW. Auditory-evoked potential studies of cortical maturation in normal hearing and implanted children: correlations with changes in structure and speech perception. Acta oto-laryngologica 123(2):249-252, 2003.

8. Ostojic S, Djokovic S, Dimic N et al. Cochlear implant-speech and languagedevelopment in deaf and hard hearing children following implantation, Vojno-sanit. Pregl. 68, 349-352, 2011. 
9. Dettman S, Pinder D, Briggs R et al. Communication developmentin children who receive the cochlear implant younger than 12 months: risks versus benefits, Ear Hear, 28, 11S-18S, 2007.

10. McConkey Robbins A, Burton Koch D, Osberger MJ et al. Effect of age at cochlear implantation on auditory skill development in infants and toddlers. Journal of Otolaryng Hand N Surg 130, 570574, 2004.

11. Schweizer M, Brachmaier J. Longitudinal assessment of early implanted children: first results. Medel Parent Guide. Presented at NHS 2006, Como, Italy.

12. Valencia D M, Rimell FL, Friedman BJ et al. Cochlear implantation in infants less than 12 months of age. Int J Pediatr Otorhinolaryngol. 72(6):767-73, 2008.

13. Kotby M, Khairy A, Baraka M, El-Shobarry A et al. Language testing of Arabic speaking children in: proceedings of the XXIII world congress of the International Association of the logopedics and pediatrics 1995.
14. El-Sady SR, El-Shoubary AM, Hafez GN, Mohammed AA. Translate, modified and standardized of Preschool Language Scale [Unpublished Thesis]. $4^{\text {th }}$ ed.: Ain Shams Medical School; 2011

15. Colletti, V., Carner, M., Miorelli, V et al. Cochlear implantation at under 12 months: Report on 10 patients. The Laryngoscope, (115), 445-449, 2005.

16. Moeller M, Hoover B, Putman $\mathrm{C}$ et al. Vocalizations of infants with hearing loss compared with infants with normal hearing: Part I - phonetic development. Ear Hear. 28(5), 605-627, 2007.

17. Stacey $\mathrm{P}$ C, Fortnum $\mathrm{H}$ M, Barton $\mathrm{G} R$ et al. Hearing impaired children in the United Kingdom. I : Auditory performance, communication skills, educational achievement, quality of life, and cochlear implantation. Ear and Hearing, 27, 161 - 186, 2006 